\title{
Indoor Lighting Customization Based on Effective Reflectance Coefficients: A Methodology to Optimize Visual Performance and Decrease Consumption in Educative Workplaces
}

\author{
Antonio Peña-García 1,*(D) and Ferdinando Salata ${ }^{2}$ (D) \\ 1 Department of Civil Engineering \& Research Group "Lighting Technology for Safety and Sustainability", \\ University of Granada, 18074 Granada, Spain \\ 2 DIAEE-Area Fisica Tecnica, Università degli Studi di Roma "Sapienza", Via Eudossiana, 18, 00184 Rome, \\ Italy; ferdinando.salata@uniroma1.it \\ * Correspondence: pgarcia@ugr.es
}

Citation: Peña-García, A.; Salata, F. Indoor Lighting Customization Based on Effective Reflectance Coefficients: A Methodology to Optimize Visual Performance and Decrease Consumption in Educative Workplaces. Sustainability 2021, 13, 119. https://dx.doi.org/10.3390/ su13010119

Received: 10 November 2020 Accepted: 22 December 2020 Published: 24 December 2020

Publisher's Note: MDPI stays neutral with regard to jurisdictional claims in published maps and institutional affiliations.

Copyright: () 2020 by the authors. Licensee MDPI, Basel, Switzerland. This article is an open access article distributed under the terms and conditions of the Creative Commons Attribution (CC BY) license (https: / / creativecommons.org/ licenses/by/4.0/).

\begin{abstract}
The importance of accurate lighting has been proven to be essential for good performance in all kinds of buildings, where most of the professional activities are carried out. National regulations and international standards dealing with indoor lighting establish the technical requirements of lighting installations to ensure the performance of their users. These requirements deal with illuminance on the working plane, uniformity, glare, color temperature of light and some other parameters. However, regulations and technical documents on indoor lighting are mainly referred to standard conditions that are sometimes far away from the reality. Hence, some installations can fulfill the technical requirements, whilst being uncomfortable for task development, impairing user's performance and are oversized in terms of energy consumption. This work departs from a field study in highlighting the regulatory limitations in the matter of reflectance, to propose a quasi-Lambertian approach to real conditions in indoor workplaces with a special aim in educative environments. It consists of the introduction of "effective reflectance" coefficients for some key visual tasks and furniture carried out by users in certain typical positions and working planes. Based on this coefficient, it is proposed to implement a simple measurement and luminary programming methodology adapted to each particular workplace, especially in educational centers. The final target is to improve visual performance and save energy.
\end{abstract}

Keywords: indoor lighting; energy savings; workplaces; efficient buildings; visual comfort; visual performance

\section{Introduction}

Indoor activities include a wide variety that goes from industrial production to education, or from medicine and surgery to leisure and entertainment. Inside this vast amount of activities, there are also habitual ones such as office work, teaching, cooking and many others.

However, there is a common link among all them: they are carried out through a more or less demanding visual task. In fact, $80 \%$ of the information we receive in our daily lives comes from the sense of vision [1]. This makes an idea about how critical an accurate lighting installation can be for task performance, safety at work, productivity, well-being and even disease avoidance.

In spite of the positive impact of accurate indoor lighting on performance and productivity [2], users' health [3,4] and others [5] at any range of age [6,7], indoor lighting requires high consumptions in energy, raw materials (manufacture of luminaries, wiring and electrical devices), and causes emissions of greenhouse gasses, solid waste needing recycling, etc. [8].

In order to ensure the correct performance in indoor activities with the lowest impact in terms of consumption, different standards and regulations have been established. These 
standards and laws regulating indoor lighting in workplaces are especially important since almost every activity can be considered as work for one or more participants. In the next section, these regulations will be briefly analyzed.

\subsection{Regulation on Indoor Working Places: State of the Art and Perspectives}

The lighting of indoor working places is regulated by different national and international laws establishing lighting requirements on the specific part of the room where the visual task must be carried out, the so-called working plane.

Thus, the European Standard EN 12464-1:2011 [9], focused on workplaces, establishes that, on the desks in schools and teaching centers there must be an average illuminance (ratio between the luminous flux received on one surface, and the area, $\mathrm{dA}$, of this surface) $E \mathrm{~m}=300 \mathrm{lux}$, whereas the average illuminance uniformity, Um, (minimum measured illuminance in a grid of points divided into $E \mathrm{~m}$ ), must be $U \mathrm{~m}>0.6$. This parameter ensures homogeneous illumination. In addition, the discomfort glare is limited to UGR $<19$ to avoid annoyance to students. The light sources must ensure a good color reproduction, $\mathrm{Ra}>80$. The requirement is similar in the desk of professors' and teachers' offices, whereas when the teaching activity is carried out on a night schedule, the requirement establishes $E \mathrm{~m}=500$ lux (same uniformity, glare and $\mathrm{Ra}$ ), which is due to the necessity to interrupt melatonin secretion and keep students awake.

These requirements are just an example showing typical recommendations in order to ensure a comfortable visual task and good performance from the installation users (students and staff in this case). Similar recommendations within this standard or even specific standards are made for other indoor working places of general [10] and specific use, such as theaters, restaurants, mounting chains in factories or sport facilities such as EN 12193:2007 [11].

As consequence, when lighting designers start a new project they must go to the national requirements and design the installation according to the relevant parameters. In parallel, when a working installation is checked for maintenance or renewal, the technicians must take measurements and make sure that they fulfill the technical requirements of the mandatory regulation.

Although the utility of the regulations on lighting is without doubt, the main parameters are referred to standard working planes and conditions where there are no observers shadowing the visual tasks, no negative interaction between electrical and natural light, etc. As pointed out by Cuttle "interior lighting practice continues to be directed towards providing uniform illumination over the horizontal working plane, irrespective of the nature of human activity" [12].

It does not mean that the regulations are useless or wrong: the range of situations in a working space can be so wide that it is impossible to make individual specifications for every situation and, hence, it is necessary to generalize in order to give an approximate idea.

However, the Lighting Community is aware of this gap between regulation and practice, and also of other open points in the long route to effectively optimize indoor lighting.

Among these open points, we consider that three have major importance and complexity; in addition, there is expected to be a research trend in the next few years in: efficient use of sunlight, control of non-visual effects, and optimal management of shadowing effects on visual tasks. The solutions to these open points necessarily go through accurate networks of sensors and communicate with relevant devices in the facility (windows, shields, dimming devices and others) [5].

Concerning the use of sunlight, different national regulations in many countries include specific recommendations on the efficiency of indoor installations such as the manual or automatic switching-off of lights when enough sunlight comes through the windows, or electrical designs allowing independent arrows of lights near the windows [13-15]. They have similarities with some variations in order to get adapted to the special features or 
culture in each country. However, daily practice shows contradictory results. The variability of sunlight through the day, the different orientations of indoor spaces with respect to the ecliptic and other factors lead to situations where curtains or shutters must be closed to avoid glare or annoying reflections on blackboards and other furniture impairing a correct development of the visual tasks. For this reason, researchers around the world are working on the development of models and tools to deal with radiative transfer involving complex surfaces [16-18] and/or daylight in buildings [19,20] in order to save energy with an optimal visual performance.

Another hot topic on indoor lighting that is a matter of active research, in order to be incorporated into regulations and regular practice, is the development of models to foresee and handle non-visual effects of light. Although some non-visual paths, such as the melatonin one, are nowadays relatively well-known, many others still have a way to go to be completely understood. So, it is necessary to take the maximum profit from indoor working installations and look for an optimal compromise between efficacy, occupant's health and well-being [21-25].

Finally, although it could seem trivial that installation's users may shadow their own or others' visual work planes, and it is obviously negative, the solution is much more complex than an optimal arrangement of furniture and work spots. Users move and change their positions throughout the day in most indoor places (offices, schools, factories, etc). These changes of position frequently come together with changes in the natural lighting when there are windows (most cases). For this reason, it is necessary to analyze shading behavior in indoor facilities. Recently, interesting models based on algorithms have been proposed, highlighting the complexity of the problem and the way to get an optimal visual performance and energy savings [26,27].

These three open points have a common link in the necessity of implementing better and more optimal networks of sensors with accurate communication protocols among them and with the devices to increase, decrease or redistribute lighting in indoor facilities [28].

Beyond these important gaps, there is one topic that has not been exhaustively treated: the inclusion of different reflectances (ratio between reflected and incident luminous flux on one given surface) of furniture and work planes in the models dealing with sunlight, nonvisual effects and shadowing. Except for some interesting works dealing with reflective properties and energy savings [29-31], in general, most research and regulations adopt the classical assumptions on reflectance in indoor facilities and workplaces without going further.

In this research, the real conditions of lighting in indoor workplaces will be studied and some approaches to improve exactitude without making the projects and measurements more complex will be proposed.

\subsection{Approximations to Reflecting Properties in Indoor Lighting Standards}

The majority of the calculation methods, analytical or computational, currently used in indoor lighting take two fundamental approximations [15]:

(1) The users are supposed to not alter visual conditions on the visual planes, that is, no shadow or reflected luminous flux due to clear clothes of people near the visual plane is considered in the models.

(2) Reflectance, $\rho$, of working planes, walls, floors and ceiling is taken as constant whatever the incidence direction and whatever the direction where the luminous flux is reflected. Standard EN 12464:2011 [9] recommends the following reflectances for most indoor surfaces reflecting as diffusers: ceiling: 0.7 to 0.9 ; walls: 0.5 to 0.8 ; floor: 0.2 to 0.4. This implies that the surfaces under consideration reflect the same luminous flux per unit of surface in one solid angle and direction, in all the directions. This flux is called Luminance, and the surfaces reflecting or emitting the same luminance in all the directions are called "lambertian surfaces" or "perfect diffusers". Although this approximation is quite useful to simplify calculations, many surfaces commonly 
present in indoor spaces, especially those with high reflectance, don't reflect the same luminance in all directions.

It is clear that these approximations are very useful to perform the calculations needed to design indoor installations in a simple and reasonable way. However, it is also clear that considering spaces without the influence of users and changing reflection properties for different directions of observation, that is, for different visual tasks, is sometimes a strong approximation.

Reflectance and the main quantities involved in indoor workspaces will be analyzed in the next section.

\section{The Basic Problem in Indoor Lighting}

Most of the visual tasks in indoor and many in outdoor lighting are carried out by reflection, that is, the visual planes are not primary, but secondary sources. The sequence can be described as follows:

(1) Luminaries emit luminous flux, $\phi$, with a given spatial distribution of luminous intensity (luminous flux within a solid angle in one given direction). This intensity can be expressed by the matrix $I(\theta, \varphi)$.

(2) The luminous flux reaches the working planes, where it can be characterized as illuminance (received luminous flux per unit of surface), E.

(3) The working planes have a certain capability to reflect the incident flux. This property is called "reflectance" and it is a function of the material, the incident angle and the reflection angle, $\rho(\alpha, \beta, \gamma, \delta)$. The spectral distribution of the reflected light depends on the reflective properties of the surface and the spectral distribution of the incident light.

(4) After surface processing, the reflected luminous flux is spread in all or some directions. The quantity taking account of the reflected flux in one given direction (the eyes of a typical observer, for instance) is the abovementioned Luminance, $L(\theta, \varphi)$

(5) The luminous flux reaching towards the observer's eye is characterized by the corneal illuminance, $\mathrm{E}_{\mathrm{cor}}$ (luminous flux received per unit of corneal surface). After refraction through the ocular media, some of this flux will reach the observers retina (retinal illuminance, $\mathrm{E}_{\mathrm{r}}$ ) to initiate the visual and non-visual paths.

The process above is valid when the observers do not have a direct sight of primary sources but carry their visual tasks after reflection on the working planes, that become secondary sources. This is the most common situation in indoor lighting, where the configuration and reflective properties of the room (floor, walls, ceiling), furniture (tables, blackboards, etc.), papers, books, and even other users of the facility, are critical.

In this scenario, the most accurate quantity to work with is the luminance, $L$. This quantity somehow takes account of the surface's brightness and is directly related to the retinal illuminance. However, working with the luminance reflected by objects is not easy because Luminance is a directional magnitude depending on the observation angle. This is logical because one given body does not reflect the same luminous flux in all the directions. The extreme example is one mirror, reflecting the incident luminous flux only in the same angle with respect to the normal. In the most general case, the luminance reflected by one table would be similar to a matrix such as:

$$
\left(\begin{array}{ccc}
L_{\theta 1} \varphi 1 & \ldots & L_{\theta n \varphi 1} \\
\ldots & \ldots & \ldots \\
L_{\theta 1} \varphi n & \ldots & L_{\theta n \varphi n}
\end{array}\right)
$$

Hence, to calculate the luminance reflected by the objects and foresee the visual performance of the tasks in indoor spaces, it necessary to characterize the reflective properties of surfaces and take some approximations. It has made it necessary to involve other quantities in the calculations. 
Although some interesting approaches have achieved good results by considering exitance-based metrics [32-34], the parameter used in the abovementioned indoor lighting standards and regulations is the illuminance of the working planes. To estimate the luminous flux reaching the observer eyes from both exitance and illuminance, assumptions on the reflective properties of the working plane are necessary. The most frequent one is the so-called Lambertian approach. It is valid in surfaces that reflect the same luminance in all the directions and, hence, the reflectance is constant. In Lambertian surfaces, also called perfect diffusers, the following property holds:

$$
L=\frac{\rho}{\pi} E
$$

where $E$ is the illuminance on the surface and $\rho$ is its reflectance defined as the ratio between reflected and incident luminous flux.

Although the approach in (2) is not strictly valid in all the situations, it is widely used in different outdoor infrastructures and in most built spaces due to the remarkable simplification introduced in calculations and the conclusions on the installation itself with reasonably good precision.

In summary, luminance and, hence, the retinal illuminance, $E_{\mathrm{r}}$, determine the amount of luminous flux having actual effect on photoreceptors, but this are not easy to determine. This is the reason why most regulations in indoor lighting express illumination requirements in terms of illuminance on the working plane.

This research presents field work, analysis and conclusions demonstrating that the Lambertian approach is not always applicable, which remarkably impacts on the luminance perceived by the users. Departing from this, an "effective reflectance" is proposed to adapt to conditions of real office work and the way to use it to dim certain luminaries and save energy.

\section{Materials and Methods}

Departing from the theoretical concepts abovementioned, the illuminance on the working planes and the reflected luminance from several angles of observation have been measured. These measurements have been carried out in the ideal conditions assumed by the standards, that is, no observers nearby the working plane, and also in real conditions where users of the installations can influence the measured value and the Lambertian approach itself (Figure 1).

The field work has been carried out in in standard facilities in the University of Granada (Spain). Their lighting installation was the most typical in most educative working spaces: embedded square luminaries with symmetric intensity distribution incorporating standard fluorescent or LED tubes, in arrangements of three or four per luminary, $\mathrm{Ra}=80$ and $\mathrm{T}_{\mathrm{cc}}=4000 \mathrm{~K}$.

The luminance from the working planes, mainly tables and furniture, has been measured with a Hagner Universal Photometer S3 in luminance mode. It had been previously calibrated in-house by the manufacturer. This luminance meter incorporates a viewing system: once the object is focused, the observer sees a black point, which covers a field of $1^{\circ}$ where luminance must be measured (Figure 2). 


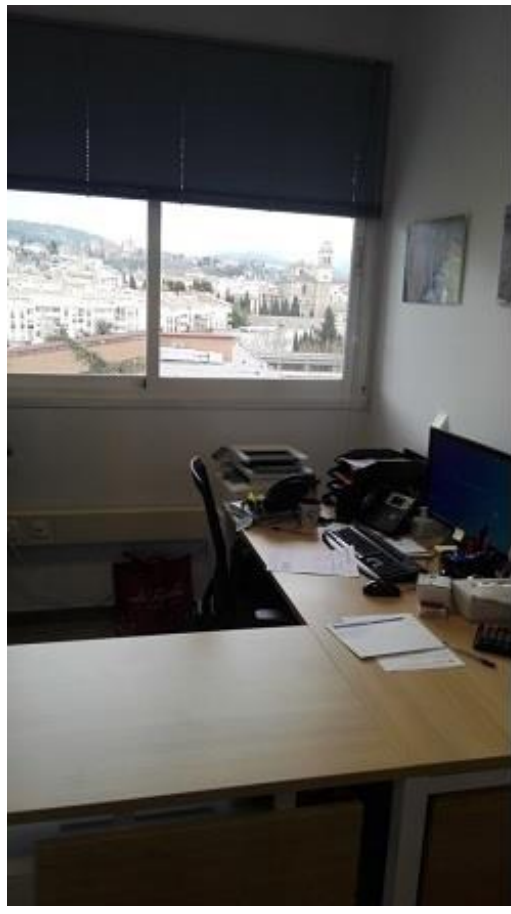

(a)



(b)

Figure 1. Visual task on a table in real work conditions without (a) and with user (b). The shadowing of the user on her own working plane is noteworthy.

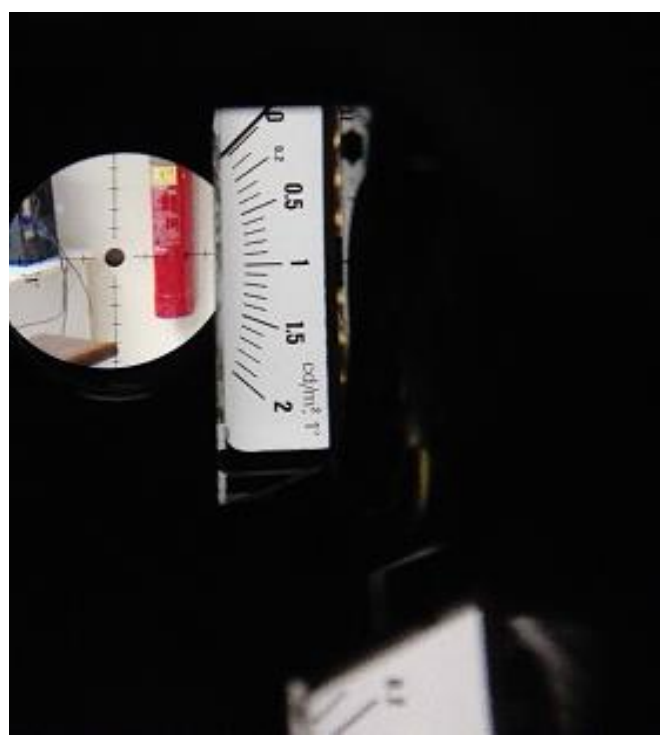

Figure 2. Viewing system of the Hagner Universal Photometer S3 in luminance mode.

The illuminance on the working plane (received flux per unit of surface) has been measured simultaneously to each luminance measurement. Although it is measured with a lux meter on the plane and, hence, it does not depend on the angle of observation, illuminance values are strongly influenced by people's movements in the room and the variability of natural light because the considered rooms also had windows. The target is to have coupled illuminance-luminance measures for each angle and thus check the applicability of the Lambertian approach. These illuminance values on the working planes have been measured with a CL 200-A lux meter also calibrated before the measurements.

From both, luminance and illuminance, the luminance and illuminance uniformities, $U_{\mathrm{m}}$ and $U_{0}$, have been calculated. Departing from all these parameters, the re- 
flectance of different working planes in typical indoor workplaces has been calculated using Equation (2) with the target of establishing a quasi-Lambertian approach. The differences and deviations from ideal to real conditions have been used to define an "effective reflectance" coefficient and propose a methodology to adapt the luminary pattern and power to each configuration, saving energy and optimizing visual performance in these indoor installations.

\section{Results}

The luminance and illuminance on different working planes in educational facilities where office and/or teaching works are carried out, have been measured from several positions of potential observers, with and without users near them. Special attention has been paid to the deviations in the measured values with and without working users near the working plane. The necessity of considering users near the visual task is duly to study real installations due to their capability to influence the natural and/or artificial lighting reaching the working planes. The luminance and the deviations depending on the measurement angle in real and ideal conditions have been considered as an indicator of the accuracy of Lambertian approach.

All these parameters are summarized in Tables 1-5. They correspond to standard furniture in offices and teaching facilities where visual tasks are frequently carried out: desks, drawing desks, low cupboards or just a simple sheet of white recycled paper.

Table 1. Wooden office desk as visual working plane in standard office.

\begin{tabular}{|c|c|c|c|c|c|c|c|c|c|c|}
\hline \multirow{2}{*}{$\begin{array}{c}\text { Wooden } \\
\text { Office } \\
\text { Desk }\end{array}$} & \multicolumn{5}{|c|}{ User Sitting in Front of Desk } & \multicolumn{5}{|c|}{ No User Sitting in Front of Desk } \\
\hline & E (lux) & $\mathbf{U}_{\mathrm{m}}$ & $\begin{array}{c}\mathrm{L}_{\text {user }} \\
\left(\mathrm{cd} / \mathrm{m}^{2}\right)\end{array}$ & $\mathrm{U}_{0}$ & $\rho$ & E (lux) & $\mathbf{U}_{\mathrm{m}}$ & $\begin{array}{c}\mathrm{L}_{\mathrm{obs}} \\
\left(\mathrm{cd} / \mathrm{m}^{2}\right)\end{array}$ & $\mathbf{U}_{0}$ & $\rho$ \\
\hline $0^{\circ}$ & 502 & \multirow{5}{*}{0.88} & 81 & \multirow{5}{*}{0.93} & 0.51 & 560 & \multirow{5}{*}{0.83} & 79 & \multirow{5}{*}{0.96} & 0.44 \\
\hline $90^{\circ}$ & 596 & & 76 & & 0.40 & 631 & & 73 & & 0.36 \\
\hline $180^{\circ}$ & 579 & & 75 & & 0.41 & 627 & & 76 & & 0.38 \\
\hline $270^{\circ}$ & 597 & & 70 & & 0.37 & 591 & & 76 & & 0.40 \\
\hline Average & 568.5 & & 75.5 & & 0.42 & 602.3 & & 76 & & 0.40 \\
\hline St. Dev. & 45.1 & & 4.5 & & 0.06 & 33.4 & & 2.5 & & 0.03 \\
\hline
\end{tabular}

Table 2. Clear office desk (Figure 2) as visual working plane in standard office.

\begin{tabular}{|c|c|c|c|c|c|c|c|c|c|c|}
\hline \multirow{2}{*}{$\begin{array}{l}\text { Clear } \\
\text { Office } \\
\text { Desk }\end{array}$} & \multicolumn{5}{|c|}{ User sitting in Front of Desk } & \multicolumn{5}{|c|}{ No User Sitting in Front of Desk } \\
\hline & E (lux) & $\mathbf{U}_{\mathrm{m}}$ & $\begin{array}{c}\mathrm{L}_{\text {user }} \\
\left(\mathrm{cd} / \mathrm{m}^{2}\right)\end{array}$ & $\mathrm{U}_{0}$ & $\rho$ & E (lux) & $\mathbf{U}_{\mathrm{m}}$ & $\begin{array}{c}\mathrm{L}_{\mathrm{obs}} \\
\left(\mathrm{cd} / \mathrm{m}^{2}\right)\end{array}$ & $\mathbf{U}_{0}$ & $\rho$ \\
\hline $0^{\circ}$ & 646 & \multirow{5}{*}{0.96} & 152 & \multirow{5}{*}{0.87} & 0.74 & 679 & \multirow{5}{*}{0.98} & 137 & \multirow{5}{*}{0.95} & 0.63 \\
\hline $90^{\circ}$ & 622 & & 141 & & 0.71 & 663 & & 134 & & 0.63 \\
\hline $180^{\circ}$ & 652 & & 162 & & 0.78 & 678 & & 131 & & 0.61 \\
\hline $270^{\circ}$ & 604 & & 165 & & 0.86 & 699 & & 125 & & 0.56 \\
\hline Average & 631.0 & & 155 & & 0.77 & 679.8 & & 131 & & 0.61 \\
\hline St. Dev. & 22.2 & & 10.9 & & 0.06 & 14.8 & & 5.1 & & 0.03 \\
\hline
\end{tabular}


Table 3. Clear brilliant drawing desk as visual working plane in standard office.

\begin{tabular}{|c|c|c|c|c|c|c|c|c|c|c|}
\hline \multirow{2}{*}{$\begin{array}{c}\text { Drawing } \\
\text { Desk }\end{array}$} & \multicolumn{5}{|c|}{ User Sitting in Front of Desk } & \multicolumn{5}{|c|}{ No User Sitting in Front of Desk } \\
\hline & E (lux) & $\mathbf{U}_{\mathrm{m}}$ & $\begin{array}{c}\mathrm{L}_{\text {user }} \\
\left(\mathrm{cd} / \mathrm{m}^{2}\right)\end{array}$ & $\mathrm{U}_{0}$ & $\rho$ & E (lux) & $\mathbf{U}_{\mathbf{m}}$ & $\begin{array}{c}\mathrm{L}_{\mathrm{obs}} \\
\left(\mathrm{cd} / \mathrm{m}^{2}\right)\end{array}$ & $\mathrm{U}_{0}$ & $\rho$ \\
\hline $0^{\circ}$ & 305 & \multirow{5}{*}{0.78} & 72 & \multirow{5}{*}{0.72} & 0.74 & 476 & \multirow{5}{*}{0.77} & 144 & \multirow{5}{*}{0.88} & 0.95 \\
\hline $90^{\circ}$ & 428 & & 92 & & 0.68 & 326 & & 111 & & 1.07 \\
\hline $180^{\circ}$ & 304 & & 112 & & 1.16 & 436 & & 109 & & 0.79 \\
\hline $270^{\circ}$ & 524 & & 125 & & 0.75 & 450 & & 129 & & 0.90 \\
\hline Average & 390.3 & & 100 & & 0.81 & 422 & & 123 & & 0.92 \\
\hline St. Dev. & 106.5 & & 23.2 & & 0.22 & 66.1 & & 16.5 & & 0.12 \\
\hline
\end{tabular}

Table 4. Top of a low office cupboard as visual working plane in standard office.

\begin{tabular}{|c|c|c|c|c|c|c|c|c|c|c|}
\hline \multirow{2}{*}{$\begin{array}{c}\text { Low } \\
\text { Office } \\
\text { Cupboard }\end{array}$} & \multicolumn{5}{|c|}{ User Near } & \multicolumn{5}{|c|}{ No User Near } \\
\hline & E (lux) & $\mathbf{U}_{\mathrm{m}}$ & $\begin{array}{c}\mathrm{L}_{\text {user }} \\
\left(\mathrm{cd} / \mathrm{m}^{2}\right)\end{array}$ & $\mathrm{U}_{0}$ & $\rho$ & E (lux) & $\mathrm{U}_{\mathrm{m}}$ & $\begin{array}{c}\mathrm{L}_{\mathrm{obs}} \\
\left(\mathrm{cd} / \mathrm{m}^{2}\right)\end{array}$ & $\mathrm{U}_{0}$ & $\rho$ \\
\hline $0^{\circ}$ & 62 & \multirow{5}{*}{0.85} & 11 & \multirow{5}{*}{0.75} & 0.56 & 94 & \multirow{5}{*}{0.78} & 22 & \multirow{5}{*}{0.87} & 0.74 \\
\hline $90^{\circ}$ & 62 & & 16 & & 0.81 & 118 & & 22 & & 0.59 \\
\hline $180^{\circ}$ & 80 & & 18 & & 0.71 & 98 & & 21 & & 0.67 \\
\hline $270^{\circ}$ & 87 & & 14 & & 0.51 & 75 & & 18 & & 0.75 \\
\hline Average & 72.8 & & 14.8 & & 0.64 & 96.3 & & 20.8 & & 0.68 \\
\hline St. Dev. & 12.7 & & 3.0 & & 0.14 & 17.6 & & 1.9 & & 0.08 \\
\hline
\end{tabular}

Table 5. Standard recycled paper as visual working plane on a desk.

\begin{tabular}{|c|c|c|c|c|c|c|c|c|c|c|}
\hline \multirow{2}{*}{$\begin{array}{c}\text { White } \\
\text { Paper on } \\
\text { Desk }\end{array}$} & \multicolumn{5}{|c|}{ User Sitting in Front of Desk } & \multicolumn{5}{|c|}{ No User Sitting in Front of Desk } \\
\hline & E (lux) & $\mathbf{U}_{\mathrm{m}}$ & $\begin{array}{c}\mathrm{L}_{\text {user }} \\
\left(\mathrm{cd} / \mathrm{m}^{2}\right)\end{array}$ & $\mathrm{U}_{0}$ & $\rho$ & E (lux) & $\mathbf{U}_{\mathrm{m}}$ & $\begin{array}{c}\mathrm{L}_{\mathrm{obs}} \\
\left(\mathrm{cd} / \mathrm{m}^{2}\right)\end{array}$ & $\mathrm{U}_{0}$ & $\rho$ \\
\hline $0^{\circ}$ & 655 & \multirow{5}{*}{0.89} & 180 & \multirow{5}{*}{0.88} & 0.86 & 662 & \multirow{5}{*}{0.98} & 181 & \multirow{5}{*}{0.98} & 0.86 \\
\hline $90^{\circ}$ & 660 & & 144 & & 0.69 & 686 & & 179 & & 0.82 \\
\hline $180^{\circ}$ & 548 & & 153 & & 0.88 & 662 & & 181 & & 0.86 \\
\hline $270^{\circ}$ & 604 & & 176 & & 0.92 & 690 & & 176 & & 0.80 \\
\hline Average & 616.8 & & 163.3 & & 0.83 & 675 & & 179.3 & & 0.83 \\
\hline St. Dev. & 52.4 & & 17.5 & & 0.10 & 15.1 & & 2.4 & & 0.03 \\
\hline
\end{tabular}

The columns in the left correspond to measures taken by the own users sitting in a chair in front of the table or standing in front of the cupboard (depending on the case). These luminance values are representative of how they actually perceive the surface where the visual task is performed and includes their own influence on it. Measures in the right columns are taken by a standing observer away from the table with no user shadowing or influencing the illumination of the visual task. These last are ideal users that have no influence but could hardly perform real work in these facilities.

A detailed analysis of Tables 1-5 shows a higher variability in luminance and reflectance values depending on the proximity of the users to the visual tasks. Table 6 summarizes the average and standard deviations in the measured luminance from each element in both situations with and without the user near. 
Table 6. Average and standard deviations in the measured luminance from all the considered surfaces with and without users influencing the lighting on the working plane.

\begin{tabular}{ccccc}
\hline \multirow{2}{*}{ Luminance from Furniture } & \multicolumn{2}{c}{ Working User in Front } & \multicolumn{2}{c}{ No Working User Near } \\
\cline { 2 - 5 } & Average & Std. Dev. & Average & Std. Dev. \\
\hline Wooden office desk & 75.50 & 4.51 & 76.00 & 2.45 \\
\hline Clear office desk & 155.00 & 10.86 & 131.75 & 5.12 \\
\hline Drawing desk & 100.25 & 23.21 & 123.25 & 16.50 \\
\hline Low office cupboard & 14.75 & 2.99 & 20.75 & 1.89 \\
\hline White paper on desk & 163.25 & 17.50 & 179.25 & 2.36 \\
\hline
\end{tabular}

The comparison between columns 3 and 5 in Table 6 shows that the measured luminance presents a remarkably higher dispersion when there are users near to the working plane, such as sitting workers in front of it, the most common situation in office working. It evidences that the presence of these users is not compatible with the treatment of such surfaces as Lambertian ones, because Lambertian surfaces are precisely those reflecting the same luminance in all the directions. These results suggest that the Lambertian approach, implicitly assumed in many standards, regulations and calculation programs, is a good approach just as long as there is no user influencing the lighting. However, this influence of the users is inherent to all the visual tasks in working environments such as offices, teaching environments and many others.

Intimately related to luminance is the reflectance of the considered surfaces. Table 7 presents the averages and standard deviations in the reflectance coefficients in Tables 1-5.

Table 7. Average and standard deviations in the reflectance of all the considered surfaces with and without users influencing the lighting on the working plane.

\begin{tabular}{ccccc}
\hline \multirow{2}{*}{ Reflectance of Furniture } & \multicolumn{2}{c}{ Working User in Front } & \multicolumn{2}{c}{ No Working User Near } \\
\cline { 2 - 5 } & Average & Std. Dev. & Average & Std. Dev. \\
\hline Wooden office desk & 0.42 & 0.06 & 0.40 & 0.03 \\
\hline Clear office desk & 0.77 & 0.06 & 0.61 & 0.03 \\
\hline Drawing desk & 0.81 & 0.22 & 0.92 & 0.12 \\
\hline Low office cupboard & 0.64 & 0.14 & 0.68 & 0.08 \\
\hline White paper on desk & 0.83 & 0.10 & 0.83 & 0.03 \\
\hline
\end{tabular}

The reflectances in Table 7 are calculated according to the Lambertian approach, usually assumed in lighting programs. This approach implies that every surface has a constant reflectance $\rho$, but it does not actually happen as shown in Table 7 . Once more, the standard deviations are higher when there are near users working in the plane.

The results in Tables 6 and 7 are mainly due to the influence of the users, who can remarkably alter the luminous flux and thus the illuminance on one table depending on the relative "observer-luminary" position. This is shown in Figure 3. 




Figure 3. Schematic configuration of the visual task depending on the luminary position for the same user and visual working plane.

The results presented above show that, rather than a constant reflectance, there is an "effective reflectance" applicable to the visual task of each user influencing the visual task with his own presence and relative position with respect to luminaries and windows. The deviations from constant reflectance can even exceed $20 \%$.

These considerations, experimentally supported by the field measurements presented in Tables 1-7, show that the assumptions made by the regulations on workplace lighting might not be so realistic as desirable.

This core problem could be solved considering the features of the furniture with the introduction of the abovementioned "effective reflectance" in a quasi-Lambertian approach. Of course, taking desks and furniture into account is not an easy task because they are not the only factor affecting the luminance distribution from the working plane. Fortunately, it is not always the same: Table 7 shows that the reflectance is more or less independent from the user and luminary's position for certain kinds of surfaces such as a recycled white paper or a wooden office desk. On the other hand, the reflectance varies significantly for brighter surfaces that have treatment to make them brighter, such as drawing desks or some kinds of very clear office desks. In these cases, the reflectance can have a variation higher than 15-20\%, depending on the relative positions between observers and luminaries.

With all these pros and cons in mind, it is proposed that the reflectance of each surface where critical tasks are carried out should be measured in order to adapt part of the beams from luminaries to the specific luminance requirements of each typical observer. The "effective reflectance" is proposed as follows:

- $\quad$ The reflectance of each main surface is measured using the Lambertian approach used in Tables 1-5.

- In surfaces with low variability (dark, wooden, etc.), the Lambertian constant reflectance is adopted.

- In surfaces showing deviations above $10 \%$, the reflectance calculated with luminance measurements from the line of sight of the most habitual user, should be adopted.

For example, according to Tables 1-5, the effective reflectance of the surfaces studied in several educative facilities presented in this work are summarized in Table 8.

As shown in Table 8, the reflectance calculated using the Lambertian approach is maintained for wooden desks and clear office desks, whereas the value measured for $0^{\circ}$ and user in front has been adopted in clearer surfaces such as drawing desks, low office cupboards and standard white paper on the desk. This can allow a realistic tuning of luminaries or certain LED arrays of them. 
Table 8. Effective reflectance of the surfaces in educational environment used in this work.

\begin{tabular}{cc}
\hline & Effective-Reflectance Working User in Front \\
\hline Wooden office desk & 0.42 \\
\hline Clear office desk & 0.77 \\
\hline Drawing desk & 0.74 \\
\hline Low office cupboard & 0.56 \\
\hline White paper on desk & 0.86 \\
\hline
\end{tabular}

This is not a hard task for maintenance staff and should be carried out only once every few years, when new installations of offices or classrooms start to work the first time or after remodeling. Then, each array of LED in luminaries can be accordingly dimmed.

Besides the consequent reduction in glare and improvement of visual performance, the energy savings achieved with this simple operation can be remarkable. According to Equation (2), an increase of just 10\% in reflectance can lead to an increase of $10 \%$ in the luminance reflected by one working plane for the same incident illuminance. However, it is also possible to keep the desired luminance decreasing the incident illuminance by $10 \%$ if we know that the reflectance is $10 \%$ higher as with some furniture in this work. We can prove this, keeping in mind that illuminance is defined as incident flux $(\Phi)$ per unit of surface, and the definition of light source efficiency, $\eta$ :

$$
\eta=\frac{\Phi}{P}
$$

where $P$ is the electrical power consumed by the source. The reflected luminance $L$ can be also expressed as:

$$
L=\frac{\eta P}{\pi S} \rho
$$

A careful consideration of Equation (4) shows that if the surface reflectance increases, for example, by $10 \%$, the consumed power of the luminaries can decrease by about this same $10 \%$ with the consequent saving in energy consumption. This is feasible because LED luminaries can be dimmed, and the flux of each LED array can be evenly adapted to the convenience of each configuration.

In summary, introducing specific reflectance factors for some kinds of furniture and relative configurations "luminaries/windows-habitual position of users" can help to adapt the luminous flux of the nearest luminaries with just some quick measurements and programming of the luminaries once the room disposal is decided. It can lead to improvements in visual performance and also to energy savings by dimming luminaries, which is habitual practice after the generalization of LED luminaries.

\section{Conclusions}

The variability of the visual conditions is much higher when installation users are near to the visual task because they influence, mainly by shadowing, the light distribution on the working plane. Depending on the arrangement of the luminaries and/or the windows, and the position of the users, their influence can be higher or lower. The extreme case is when the user is sitting working on a table opposite to a window in days with high natural luminance.

In this work, the differences between ideal conditions without users near to the working plane, and real conditions where users influence the distribution of light on the working plane, are analyzed after field measurements. The results show that the constant reflectance assumed by the Lambertian approach, adopted by many programs and standards, is not applicable when users are near to the working plane.

To overcome this situation, a quick determination of an "effective reflectance" for certain working planes and typical observers and consequent customization of luminaries 
beams, is proposed: once the furniture, positions of work and luminaries are installed, the maintenance staff can quickly determine the effective reflectance when users are working at their sites and introduce it, adjusting the luminance with Equation (4) presented in this work. This makes it possible to calculate the needed power to achieve the necessary luminance and dim luminaries for the sake of energy saving and optimized lighting levels. The multiple possibilities of current LED luminaries with regard to their emission patterns, the possibility to increase or reduce the light emission of the LED luminaire as a whole or the possibility to modify the emission of each type of light emitter within a single LED luminaire, clearly permits the proposed way to adjust the lighting environment in working sites.

This methodology is especially useful in indoor facilities with high energy consumption and visual load also having maintenance staff for implementation, such as educational centers.

Author Contributions: Conceptualization, A.P.-G.; methodology, A.P.-G. and F.S.; resources, A.P.-G.; writing —original draft preparation, A.P.-G. and F.S.; funding acquisition, A.P.-G. All authors have read and agreed to the published version of the manuscript.

Funding: This research has been possible thanks to the cooperation between the University of Granada (Spain) and Sapienza University of Rome (Italy). In particular, it was materialized through the stay of Prof. Peña-Garcíaat Sapienza's Area di Fisica Tecnica. The stay was funded by Sapienza's visiting professors' competitive program in 2018.

Informed Consent Statement: Informed consent was obtained from all the subjects involved in the study.

Acknowledgments: The authors thank Noelia Moya Busto for assistance related to the furniture and offices at the University of Granada.

Conflicts of Interest: The authors declare no conflict of interest.

\section{References}

1. Haupt, C.; Huber, A.B. How axons see their way-Axonal guidance in the visual system. Front Biosci. 2008, 13, 3136-3149. [CrossRef]

2. Juslén, H.; Wouters, M.; Tenner, A. The influence of controllable task-lighting on productivity: A field study in a factory. Appl. Ergon. 2007, 38, 39-44. [CrossRef]

3. Kraneburg, A.; Franke, S.; Methling, R.; Griefahn, B. Effect of color temperature on melatonin production for illumination of working environments. Appl. Ergon. 2017, 58, 446-453. [CrossRef]

4. Dehoff, P. The impact of changing light on the well-being of people at work. In Proceedings of the 5th European Conference on Energy-Efficient Lighting, Nice, France, 29-31 May 2002; pp. 351-374.

5. Peña-García, A.; Salata, F. The perspective of Total Lighting as a key factor to increase the Sustainability of strategic activities. Sustainability 2020, 12, 2751. [CrossRef]

6. Wang, Y.; Huang, H.; Chen, G. Effects of lighting on ECG, visual performance and psychology of the elderly. Optik 2020, 203, 164063. [CrossRef]

7. Moyano, D.B.; Fernández, M.S.J.; Lezcano, R.A.G. Towards a sustainable indoor lighting design: Effects of artificial light on the emotional state of adolescents in the classroom. Sustainability 2020, 12, 4263. [CrossRef]

8. Montoya, F.G.; Peña-García, A.; Juaidi, A.; Manzano-Agugliaro, F. Indoor Lighting Techniques: An overview of evolution and new trends for energy saving. Energy Build. 2017, 140, 50-60. [CrossRef]

9. European Committee for Standardization (CEN). Light and Lighting. Lighting of Work Places. Part 1: Indoor Work Places; European standard EN 12464-1:2011; European Committee for Standardization: Bruxelles, Belgium, 2011.

10. International Organization for Standardization (ISO). Lighting of Work Places_Part 1: Indoor; ISO 8995-1:2002; International Organization for Standardization: Geneva, Switzerland, 2002; p. 18.

11. European Committee for Standardization (CEN). Light and Lighting. Sport Lighting; European Standard EN 12193:2007; European Committee for Standardization: Bruxelles, Belgium, 2007.

12. Cuttle, C.A. fresh approach to interior lighting design: The design objective - direct flux procedure. Light. Res. Technol. 2018, 50, 1142-1163. [CrossRef]

13. The Spanish Technical Building Code. Available online: https://www.eukn.eu/news/detail/spanish-technical-building-code-1/ (accessed on 8 November 2020).

14. Government of Italy. Health Ministerial Decree. Available online: https://www.esteri.it/mae/resource/doc/2020/06/decree_ of_the_italian_prime_minister_of_june_11_2020.pdf (accessed on 8 November 2020). 
15. Polish Ministry of Infrastructure and Construction. Available online: https://www.export.gov/apex/article2?id=PolandInfrastructure-Intelligent-Transportation-Systems (accessed on 8 November 2020).

16. Moon, P.H. The Scientific Basis of Illumination Engineering; Dover Publications: New York, NY, USA, 2008.

17. Cabeza-Lainez, J.M.; Pulido-Arcas, J.A. New configuration factors for curved surfaces. J. Quant. Spectrosc. Radiat. Transf. 2013, 117, 71-80. [CrossRef]

18. Salguero-Andújar, F.; Cabeza-Lainez, J.M. New Computational Geometry Methods Applied to Solve Complex Problems of Radiative. Transf. Math. 2020, 8, 2176.

19. Costanzo, V.; Evola, G.; Marletta, L.; Nascone, F.P. Application of Climate Based Daylight Modelling to the Refurbishment of a School Building in Sicily. Sustainability 2018, 10, 2653. [CrossRef]

20. Costanzo, V.; Evola, G.; Marletta, L. A Review of Daylighting Strategies in Schools: State of the Art and Expected Future Trends. Buildings 2017, 7, 41. [CrossRef]

21. Dai, Q.; Cai, W.; Shi, W.; Hao, L.; Wei, M. A proposed lighting-design space: Circadian effect versus visual illuminance. Build. Environ. 2017, 122, 287-293. [CrossRef]

22. Cai, W.; Yue, J.; Dai, Q.; Hao, L.; Lin, Y.; Shi, W.; Huang, Y.; Wei, M. The impact of room surface reflectance on corneal illuminance and rule-of-thumb equations for circadian lighting design. Build. Environ. 2018, 141, 288-297. [CrossRef]

23. Lucas, R.J.; Peirson, S.N.; Berson, D.M.; Brown, T.M.; Cooper, H.M.; Czeisler, C.A.; Figueiro, M.G.; Gamlin, P.D.; Lockley, S.W.; O'Hagan, J.B.; et al. Measuring and using light in the melanopsinage. Trends Neurosci. 2014, 37, 1-9. [CrossRef] [PubMed]

24. Golasi, I.; Salata, F.; de LietoVollaro, E.; Peña-García, A. Influence of lighting colour temperature on indoor thermal perception: A strategy to save energy from the HVAC installations. Energy Build. 2019, 185, 112-122. [CrossRef]

25. Bellia, L.; Pedace, A.; Barbato, G. Lighting in educational environments: An example of a complete analysis of the effects of daylight and electric light on occupants. Build. Environ. 2013, 68, 50-65. [CrossRef]

26. Ding, Y.; Ma, X.; Wei, S.; Chen, W. A prediction model coupling occupant lighting and shading behaviors in private offices. Energy Build. 2020, 216, 109939. [CrossRef]

27. Yao, J. Determining the energy performance of manually controlled solar shades: A stochastic model-based co-simulation analysis. Appl. Energy 2014, 127, 64-80. [CrossRef]

28. Wagiman, K.R.; Abdullah, M.N.; Hassan, M.Y.; Radzi, N.H.M. A new optimal light sensor placement method of an indoor lighting control system for improving energy performance and visual comfort. J. Build. Eng. 2020, 30, 101295. [CrossRef]

29. Durmus, D.; Davis, W. Optimising Light Source Spectrum for Object Reflectance. Opt. Express 2015, 23, A456-A464. [CrossRef] [PubMed]

30. Pracki, P.; Dziedzicki, M.; Komorzycka, P. Ceiling and Wall Illumination, Utilance, and Power in Interior Lighting. Energies 2020, 13, 4744. [CrossRef]

31. Leccese, F.; Salvadori, G.; Montagnani, C.; Ciconi, A.; Rocca, M. Lighting assessment of ergonomic workstation for radio diagnostic reporting. Int. J. Ind. Ergon. 2017, 57, 42-54. [CrossRef]

32. Cuttle, C. Towards the Third Stage of the Lighting Profession. Light. Res. Technol. 2010, 42, 73-93. [CrossRef]

33. Cuttle, C. A New Direction for General Lighting Practice. Light. Res. Technol. 2013, 45, 22-39. [CrossRef]

34. Cuttle, C. Lighting Design: A Perception-Based Approach; Routledge: Abingdon, VA, USA, 2015. 